\title{
INVESTIGATION ON CHAR RESIDUES AND MEAN REACTIVITY OF COMPRESSION MOLDED RICE AND COFFEE HUSKS BIO- CHAR REINFORCED POLYPROPYLENE
}

\author{
Vianney Andrew Yiga ${ }^{1 *}$, Michael Lubwama ${ }^{1,2}$, Peter Wilberforce Olupot ${ }^{1}$ \\ ${ }^{1}$ Department of Mechanical Engineering, Makerere University, Kampala, Uganda \\ ${ }^{2}$ Africa Centre of Excellence in Materials, Product Development and Nanotechnology, \\ MAPRONANO, Makerere University, Kampala, Uganda
}

\begin{abstract}
Fiber-reinforced plastics have gained utilization in recent years for many applications because they are a cheaper alternative to the ordinary petroleum-derived materials. On the other hand, considerable amounts of agricultural wastes still lack enough utilization. In this study, bio-chars of husks from two rice and two coffee varieties in Uganda were utilized as fillers to reinforce polypropylene (PP) and thus develop fiber-reinforced plastics. Bio-char filler material was varied between $0 \%$ and $20 \%$. The plastics were prepared via melt mixing followed by compression molding. Effects of bio-char content on the thermal stability of the developed plastics were studied by use of an Eltra Thermostep Thermogravimetric analyzer. Thermogravimetric analysis (TGA) results showed that inclusion of biochar improved the thermal stability of the developed fiber-reinforced plastics. Maximum rate of weight loss ranged from $-0.0414 \% / \mathrm{min}$ (for $15 \%$ unmodified Wita- 9 rice bio-char) to $0.0023 \% / \mathrm{min}$ (for pure PP), corresponding to respective peak temperatures of $680.8{ }^{\circ} \mathrm{C}$ and $604{ }^{\circ} \mathrm{C}$ respectively. Peak temperatures generally increased with increase in filler loading. It was found out by this study that incorporation of bio-char fiber material resulted in increased char residues. These residues tended to hinder combustion. The highest char residues $(17.4 \%)$ were obtained when PP was loaded with $15 \%$ neutral Wita-9 rice husks bio-char. The highest mean reactivity attained was $6.1 \times 10^{-5} \% /$ minute $/{ }^{\circ} \mathrm{C}$ obtained when $10 \%$ unmodified Pussa rice husks bio-char was used to reinforce PP.
\end{abstract}

KEY WORDS: Bio-char, coffee husks, fiber-reinforced plastics, rice husks, TGA.

\section{INTRODUCTION}

Fillers from various origins and sources have been incorporated in polypropylene as means of achieving enhanced material properties and/or as a means of cost saving. Fillers may be inorganic or organic [1]. Organic fillers based on agricultural origin are composed mainly of cellulose, lignin, and hemicellulose [2]. Their dominance as reinforcing fillers in the production of fiber-reinforced plastics roots from their inexpensiveness, renewable nature, non-abrasiveness and minimal environmental pollution $[1,3,4]$. Two examples of organic fillers based on agricultural origin are rice husks and coffee husks. Much as there are some challenges and limitations exhibited by use of agricultural fillers in their raw form, a few treatments have been noted to significantly enhance their properties. One such treatments is carbonization. Carbonization forms bio-char. Biochar is a carbon-rich solid residue obtained upon heating biomass material under oxygen-deficient conditions [5]. Fiber-reinforced plastics based on uncarbonized rice husks and coffee husks have cited numerous pros to society because of their good mechanical properties. Some examples include: 
Yiga et al., (2019) used rice husks and coffee husks as filler material in the production of fiber-reinforced PP. Tensile strengths and percentage elongations varied high above $27.4 \mathrm{MPa}$ and $2.4 \%-70.3 \%$ respectively. High impact strengths and Young's moduli were achieved [2]. Tan et al., (2017) developed biocomposites based on coffee waste and HDPE. Tensile strengths and moduli increased (10 MPa - 20 MPa) with increasing filler treatment time but decreased with increase in filler loading [6]. Reis et al., (2015) manufactured biocomposites based on coffee husks waste with Polyhydroxybutyrate. Tensile strengths, Young's moduli and Izod strength of the composites increased significantly at higher coffee parchment filling ratios [7].

Chen et al., (2018) manufactured composites from rice husk recycled HDPE and polyethylene terephthalate (PET). Composites' flexural properties showed linear increases with filler content [8]. Yaacab et al., (2016) developed paddy straw powder reinforced polylactic acid (PLA). Up to $15 \mathrm{wt}$. \% of filler, tensile strengths of the biocomposites were above $30 \mathrm{MPa}$ whereas elongations at break ranged between $2 \%-3 \%$. Young's modulus increased with increase in filler material [9]. Chen et al., (2015) showed that tensile strengths and Young's modulus improved for unmodified rice husk flour reinforcements in a recycled polymer blend of HDPE and PET. Increased filler reduced elongations at break but alkali treatment enhanced these and the impact strengths [10]. Atuanya et al., (2013) developed composites based on rice husks and recycled low density polyethylene (PE) mixed with pure PE. Mechanical properties increased with increasing filler contents [11]. Fávaro et al., (2010) manufactured composites from post-consumer high-density PE with rice husk fillers. Increasing filler contents increased composites' flexural moduli, tensile and Izod impact strength [12].

Yussuf et al., (2010) developed composites based on PLA/Kenaf and PLA/Rice husk. Addition of rice husks filler material led to increased flexural modulus of PLA from 3.4 GPa to 4 GPa [13]. Rosa et al., (2009) manufactured rice husk flour-PP by melt extrusion. Tensile strengths decreased with filler loading but coupling agent improved this property. Unlike elongations at break, Young's moduli increased with increase in filler loading [14]. Yang et al. (2007) used rice husks as filler material and observed that tensile strengths of rice husks polymer composites decreased with increasing filler loading but increased with compatibilization [4]. Premalal et al., (2002) showed that apart from elongations, rice husk powder-filled PP had lower mechanical properties than talc-filled PP [1].

A major disadvantage related to fiber-reinforced plastics based on uncarbonized rice and coffee husks material however, is their high flammability $[15,16]$. Recently, flammability properties of fiber-reinforced plastics have been enhanced by incorporation of fire retardant additives, such as boron compounds [17], magnesium hydroxide [18], phosphorous-based compounds [16,19,20] and halogen [21]. To a great extent, these additives retard flammability, but have outlier disadvantages like production of dense smoke and corrosive combustion by-products during production. These have a negative impact on the environment [22]. Bio-char burns with little or no smoke because of its low volatile matter content [5].

The problem of high flammability of fiber-reinforced plastics developed with agricultural fillers in their raw form can be countered by use of bio-char from these materials as filler to transfer load. Additionally, bio-char has the ability to enhance mechanical properties like tensile strength and Young's modulus of fiber-reinforced plastics due to its hydrophobic nature $[16,23,24]$. This study therefore focused on developing fiber-reinforced plastics using compression molding with PP as matrix and modified, neutral and unmodified rice and coffee husks bio-chars as filler materials. Pre-treatment of the bio-chars was onset by use of $\mathrm{NaOH}$. Thermal properties of the developed fiber-reinforced PP were determined using an Eltra Thermostep Thermogravimetric analyzer. 


\section{MATERIALS AND METHODS}

\subsection{Materials}

Polypropylene (grade PP H032 TF) with a melt flow index of $3.0 \mathrm{~g} / 10 \mathrm{~min}$ and density of $0.9 \mathrm{~g} / \mathrm{cm}^{3}$, supplied by Somochem Uganda Ltd, Kampala, Uganda. Distilled water and $\mathrm{NaOH}$ pellets (product code 211687) with a solubility of $1090 \mathrm{~g} / \mathrm{l}$ in water at $20{ }^{\circ} \mathrm{C}$ were supplied by Lab Access Uganda Limited, Kampala, Uganda. Both Pussa and Wita-9 rice husks were supplied by Kibimba Limited in Uganda. Arabica and Robusta coffee husks were obtained from Buginyanya Zonal Agricultural Research and Development Institute, Mbale District, and Mukono Zonal Agricultural Research and Development Institute, Mukono District, respectively.

\subsection{Preparation}

The raw material rice husks and coffee husks were first sun-dried to reduce their initial moisture content to less than $13 \%$. After sun-drying, a carbonization process was employed to form bio-char. During the carbonization process, holes on the carbonizer drum were covered with mud/clay to limit the amount of air available for complete combustion of husks in the carbonizer [5]. After carbonization, bio-char was divided into three series: One part was used as is. This constituted the unmodified filler material. The second part was modified by immersion in a distilled water for 3 hours, followed by drying at room temperature for 48 hours and sun-drying for 6 days. This constituted the neutral filler material. The third part was modified by immersion in a $\mathrm{NaOH}$ solution of liquor ratio $15: 1$ for 3 hours, after which drying at room temperature for 48hours and sun-drying for 6 days was effected. The resultant bio-chars were centrifuged and washed in multiple cycles with reverse osmosis water until a neutral $\mathrm{pH}$ was attained. This constituted the modified filler material. The bio-chars were then milled to $<0.5 \mathrm{~mm}$ sizes before being used as filler material in composite processing. This treatment was carried out for both rice and coffee husks bio-chars.

Polypropylene was melted with various ratios $(0 \%, 5 \%, 10 \%, 15 \%$ and $20 \%$ by mass $)$ of different rice and coffee bio-chars in a compression molding machine to obtain circular boards of $250 \mathrm{~mm}$ diameter. Uniform mixing between the filler and matrix materials was achieved by a motor attached to the compression rig. The residence time for bio-composite preparation at $195^{\circ} \mathrm{C}$ during compression molding was 10 min. Compression was effected by use of a hand-screw jerk for 10 minutes under about $7 \mathrm{MPa}$ loading. The boards developed were then air-cooled and stored before thermal characterization.

\subsection{Characterization}

Thermogravimetric analysis (TGA) was carried out on an Eltra Thermostep thermogravimetric analyzer under nitrogen atmosphere at a heating rate of $20{ }^{\circ} \mathrm{C} / \mathrm{min}$ and a temperature range from room temperature to 1000 ${ }^{\circ} \mathrm{C}$. This analysis provided thermal explanations in terms of the burning rates, weight losses, peak temperatures, char residues, reactivity and Differential Thermogravimetry. Burning rates and mean reactivities were calculated using Equations (1) and (2) respectively.

$$
B_{R}=\frac{\left(W_{i}-W_{0}\right)}{t_{i}} \quad(\% / \mathrm{min})
$$

Where $B_{R}$ is Burning rate, $W_{i}$ is Weight at time $i, W_{0}$ is initial weight and $t_{i}$ is the time it takes for the initial weight to reach $W_{i}$.

$$
M_{R}=\frac{\mathrm{DTG}_{\min }}{T_{\text {peak }}}\left(\% / \mathrm{min} /{ }^{\circ} \mathrm{C}\right)
$$

Where $M_{R}$ is Mean reactivity, $\mathrm{DTG}_{\text {min }}$ is the maximum decomposition rate of change in weight and $T_{\text {peak }}$ is peak temperature.

\section{RESULTS AND DISCUSSION}

\subsection{Burning rate}


Burning rates of the developed bio-char fiber-reinforced PP are shown in Figure 1. The highest burning rates reached with increasing time were $0.0425 \% / \mathrm{min}, 0.0397 \% / \mathrm{min}, 0.0375 \% / \mathrm{min}$ and $0.0349 \% / \mathrm{min}$ for $10 \%$ unmodified Pussa rice husks bio-char reinforced PP, $15 \%$ unmodified Wita-9 rice husks bio-char reinforced PP, $20 \%$ unmodified Arabica coffee husks bio-char reinforced PP and $10 \%$ unmodified Robusta coffee husks bio-char reinforced PP respectively. In fact, because unmodified rice husks bio-char reinforced PP have highest burning rates reached, these particular plastics made with them undergo the greatest changes in weight per minute when temperatures reach $680.8{ }^{\circ} \mathrm{C}$ and $662.4{ }^{\circ} \mathrm{C}$ for $10 \%$ unmodified Pussa rice husks bio-char, $15 \%$ unmodified Wita-9 rice husks bio-char respectively (see Figures $2 \mathrm{~b}$ and $2 \mathrm{~d}$ ). A closer observation of Figure 1 shows that in the first four minutes, burning rates for the developed fiber-reinforced PP steadily increase, attributed to the addition of igniter gas to the TG analyzer, before decelerating in the next two minutes to reach plateau. In the accelerating phase at this time, rice husks caused a steeper rise compared to coffee husks. This could be attributed to the fact that rice husks have less moisture contents compared to coffee husks as reported in Yiga et al., (2019) [2]. Low moisture contents have a positive correlation with combustion $[25,26]$.
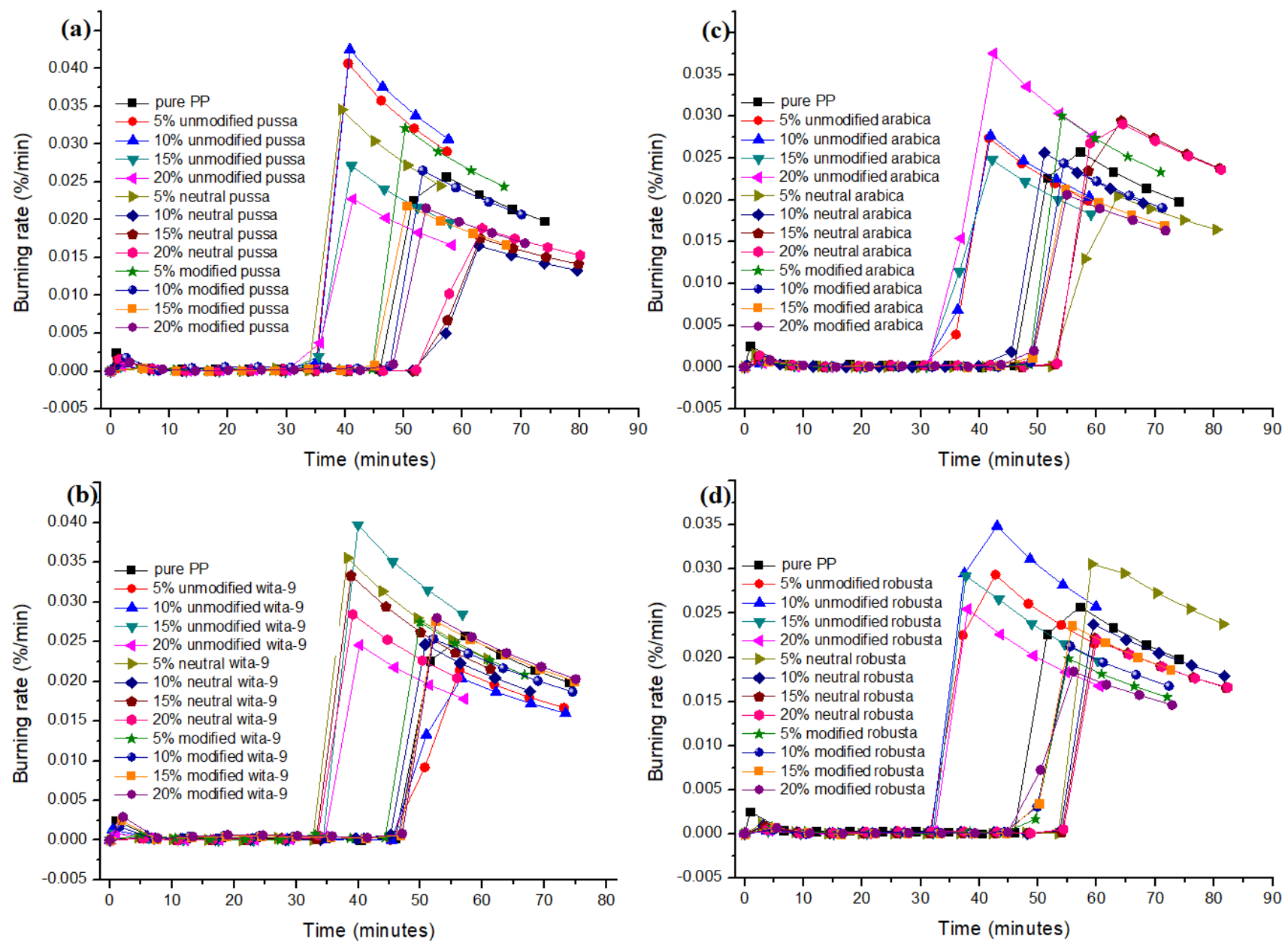

Fig. 1: Burning acceleration for bio-char reinforced PP a) Pussa rice b) Wita-9 rice c) Arabica coffee d) Robusta coffee

For most developed fiber-reinforced PP, plateau lasts up to about between 25 and 49 minutes, owing to the decomposition of hemicellulose [27]. The plateau phase of burning acceleration is generally shorter for unmodified bio-char reinforced PP because unmodified bio-char residues have lower hemicellulose compared to modified bio-char residues [2]. As time increased, the burning rates were reduced, owing to a fully developed bonded char structure, reducing the volatile products drastically, leading to thermal and flame 
protection of the matrix (PP) material [28]. One major note should be to the effect that the modification process leads to a reduction in burning rates of the developed fiber-reinforced PP. The reduction is attributed to the increasing lignin levels when these fillers are pre-treated with $\mathrm{NaOH}$ [2]. Lignin plays a major role in charformation which reduces flammability [29].

\subsection{Weight Loss and DTG}

Figures 2 and 3 show representations (thermograms) of changes in weight of the developed bio-char reinforced $\mathrm{PP}$ with increasing temperatures as well as the first derivative of the weight loss curve. All the developed fiberreinforced plastics showed an initial increase in weight from about $26^{\circ} \mathrm{C}$ to $106{ }^{\circ} \mathrm{C}$ owing to addition of igniter gas to the thermogravimetric analyzer. Pure PP starts degrading at $455^{\circ} \mathrm{C}$, associated with the degradation of hemicelluloses while inclusion of filler material shifts the onset of degradation to up to $580{ }^{\circ} \mathrm{C}$, depending on the specific fiber material and ratio loading [30]. After this temperature, thermal-degradation begins due to the rupture of the C-C bonds of the main chain [31]. Between $455{ }^{\circ} \mathrm{C}$ and $604{ }^{\circ} \mathrm{C}$, celluloses are degraded from the plastic while lignins degrade at much higher temperatures between $604{ }^{\circ} \mathrm{C}$ and $916{ }^{\circ} \mathrm{C}$. Among all components of polymers, hemicellulose is the most reactive and as a result, the temperature range of devolatilization is very narrow compared to that of lignin which occurs in a wider range [32]. It has been noted that composites made with natural fibers degraded at lower temperatures than glass and glass fiber composites but the carbonization process in this study tends to increase the temperatures at which composites made with rice and coffee husks bio-chars degrades [33].
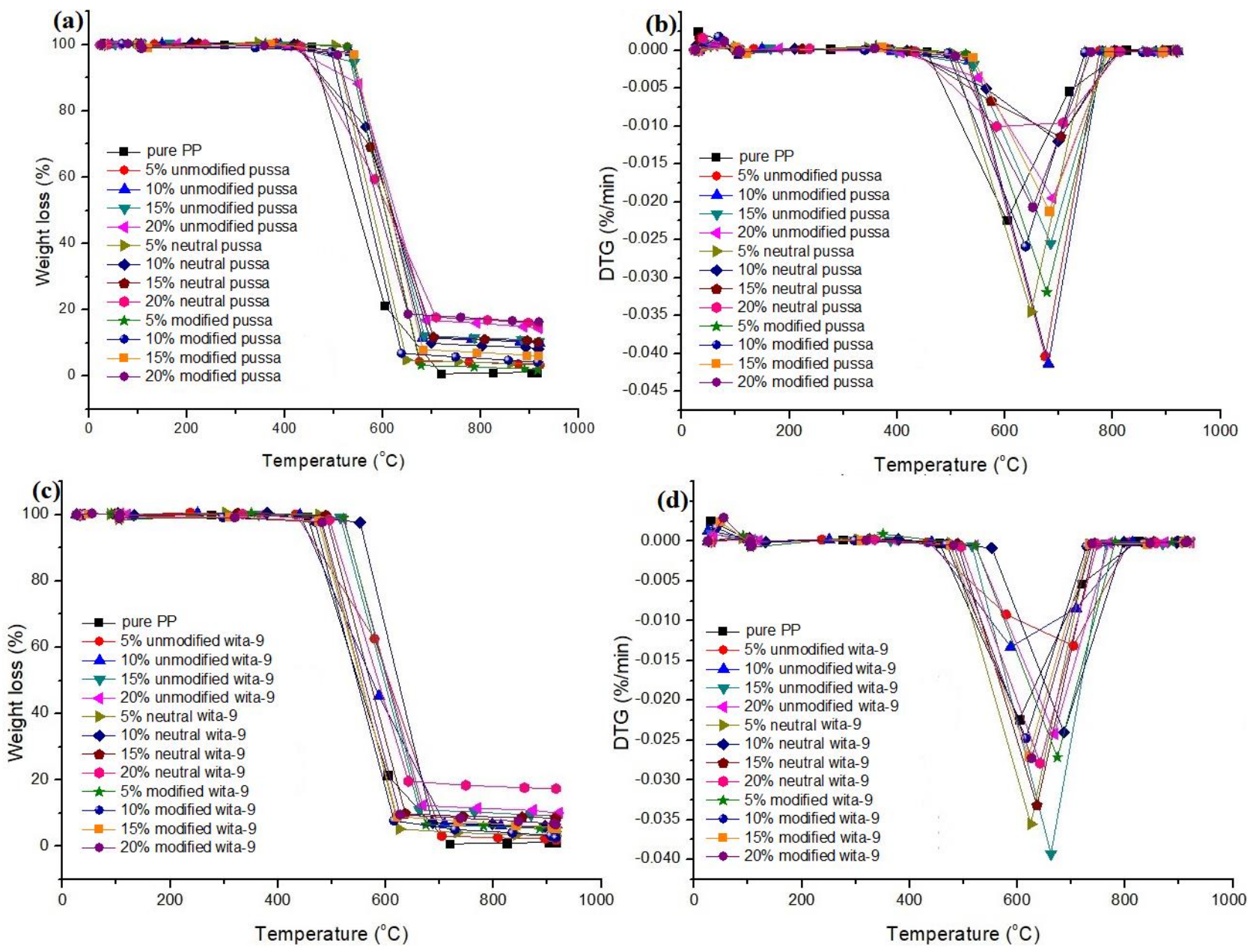

Fig. 2: Weight loss (a, c) and DTG (b, d) for bio-char reinforced PP; (a, b) Pussa (c, d) Wita-9 
The thermograms for the developed fiber-reinforced PP showed a one-stage degradation process similar to that of pure PP. Similar to what was obtained by other researchers, mass losses for all the developed fiberreinforced PP became constant over about $600{ }^{\circ} \mathrm{C}$, indicating the formation of stable carbonaceous residues [34,35]. Aside from the filler material being made of bio-char, combustion at higher temperatures produces more char, which acts as an insulating layer against further thermal degradation [36]. In fact, char formation improves the thermal resistance of the developed fiber-reinforced PP as it cuts down release of combustible volatiles and acts as a barrier to the combustible gases generated by the polymer matrix degradation. This in turn hinders the access of oxygen to the surface of the polymer matrix [34].

The derivative of the mass loss per unit time as a function of temperature was studied to investigate the thermal degradation due to the different filler loadings and treatment means. DTG thermograms show the decomposition maximums in single peaks owing to the degradation of cellulose [30]. Figures $2 b, 2 d, 3 b$ and $3 \mathrm{~d}$ clearly illustrate that the derivative for the maximum rate of decomposition is much lower for fiberreinforced PP compared to that of pure PP. This means that is its far harder to combust fiber reinforced PP as compared to pure PP. It is also clear from the thermographs that increase in filler loading and fiber treatment tends to produce a right-hand shift in the temperature (from the $604{ }^{\circ} \mathrm{C}$ obtained in pure PP) at which maximum degradation of the plastics occurs. This shows that thermal stability improves with increase in fiber loading as well as with alkali pre-treatment of the bio-chars. Wang et al., (2018), Saba et al., (2018) and Rahman et al., (2019) obtained similar results [27, 35, 37]. Such results signify that these plastics can be used in production of electrical appliances like cable housings due to high currents that they transmit.
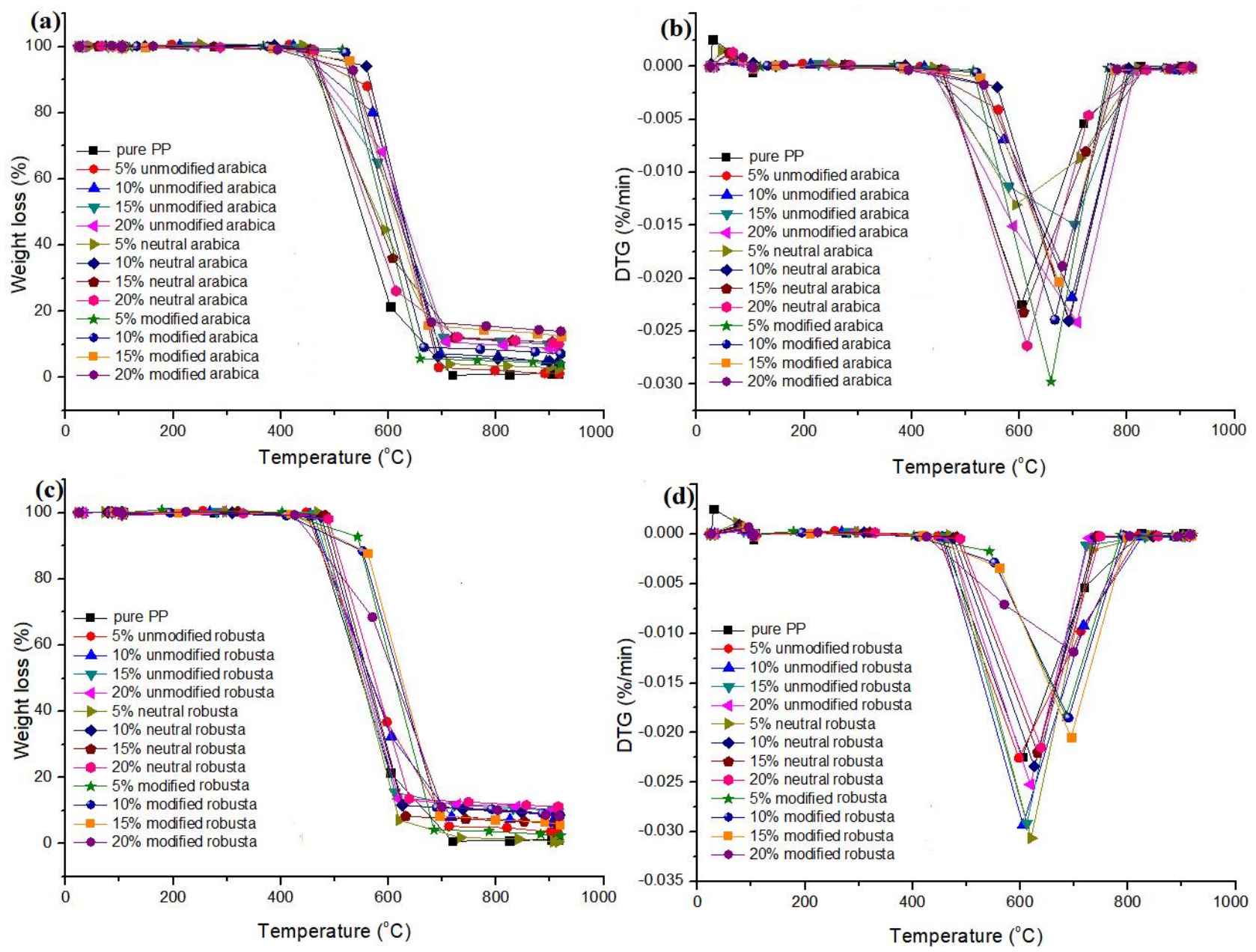

Fig. 3: Weight loss (a, c) and DTG (b, d) for bio-char reinforced PP; (a, b) Arabica (c, d) Robusta 


\subsection{Peak Temperatures}

Results for temperatures at maximum weight loss (peak temperatures) for the developed fiber-reinforced PP are shown in Figure 4. This peak temperature is considered a measure of the reactivity of a sample [38]. Peak temperatures generally increased with increase in fiber loading. This is attributable to the fact that filler material increases char residues in the plastics which tends to hinder combustion. Similar results were obtained by Saba et al., (2017) [35]. In fact, increase in bio-char fiber material in the PP matrix led to a more sluggish rate of weight loss (see Figures 2 and 3), thus reaching maximum values of weight loss at higher temperatures. Similar results were achieved by Das et al., (2016) with the use of waste derived bio-chars [30]. The increase in peak temperatures with increase in fiber loading is also attributable to a reduction in the amount of meltable matrix $(\mathrm{PP})$ which raises the temperatures at maximum weight losses.

When filler material was pre-treated, it was observed that apart from use of Arabica bio-char, there was a general reduction in peak temperatures. This means that the alkali pre-treatment process reduces the temperature at which maximum rate of change in weight occurs. This is attributable to the fact that upon alkali pre-treatment, the fiber material became more hydrophobic and thus increased the possibility to adhere with the matrix. Similar results were achieved by Lin et al., (2018) when alkali pre-treatment was effected on bamboo fibers [39].
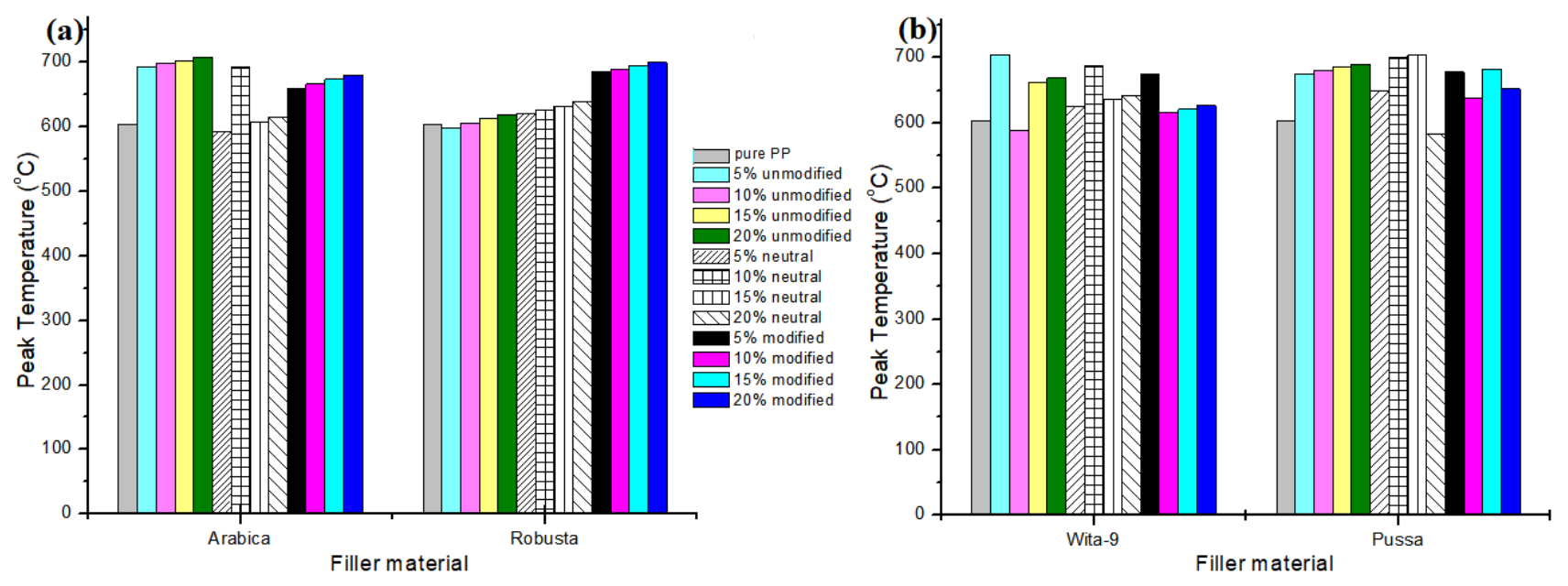

Fig. 4: Peak Temperatures obtained during bio-char reinforced PP combustion a) coffee husks b) rice husks

\subsection{Char residues}

Char residues are material left out after the completion of the combustion process during thermogravimetric analysis. Results for the remaining char residues at the maximum combustion temperatures for the developed fiber-reinforced PP are shown in Figures 5-7. The highest char residues (17.4\%) were obtained when PP was loaded with $15 \%$ of neutral Wita-9 rice husks bio-char. Incorporation of bio-char fiber material resulted in increased char residues. This is because the fiber material exerted a strong barrier effect on thermal degradation, thereby delaying weight loss for thermal degradation products as well as providing an insulative layer for the PP matrix [40, 41]. This is what improves the thermal stability of a fiber-reinforced plastic. Similar results were obtained by Molaba et al., (2018), Feng et al., (2013), Jacob et al., (2010) and Kabir et al., (2012) [16,42-44].

For Arabica coffee husks biochar reinforced PP, fiber alkali pre-treatment led to an increase in the char residues after combustion while for Robusta coffee husks biochar reinforced PP, a decrease was observed when alkali pre-treatment was effected (see Figures $5 \mathrm{~b}, 6 \mathrm{~b}$ and $7 \mathrm{~b}$ ). For Wita-9 rice husks biochar reinforced PP, at $5 \%$ filler loading, a $62 \%$ increase in char residues was observed as a result of alkali pre-treatment, thereafter, the effect of alkali pre-treatment was a reduction in the char residues obtained after combustion. For Pussa rice husks bio-char reinforced PP, alkali pre-treatment decreased char residue formation till the $20 \%$ filler loading 
when it reached $16.4 \%$ compared to $14.5 \%$ obtained when Pussa rice husks bio-char was unmodified (see Figures 5a, 6a and 7a). The reduction in char residues of the developed plastics due to alkali pre-treatment of Robusta coffee, Wita-9 and Pussa rice bio-char was attributed to the fact that alkali pre-treatment removed all impurities from the fiber material, making it remain mainly with hemicellulose, lignin and cellulose material in its structure [45,46]. The char residues obtained in the current study are higher than those obtained in previous works which were based on investigating the effect of uncarbonized rice and coffee husk fillers in PP matrix material [2]. This is attributable to the fact that use of bio-char provides double advantages as it is an inherent insulating layer which becomes even more insulative at temperatures above $600{ }^{\circ} \mathrm{C}$ [47]. One common finding is that $3 \%$ alkali pre-treatment leads to a reduction in the amount of residues after combustion of the developed fiber-reinforced PP [2].
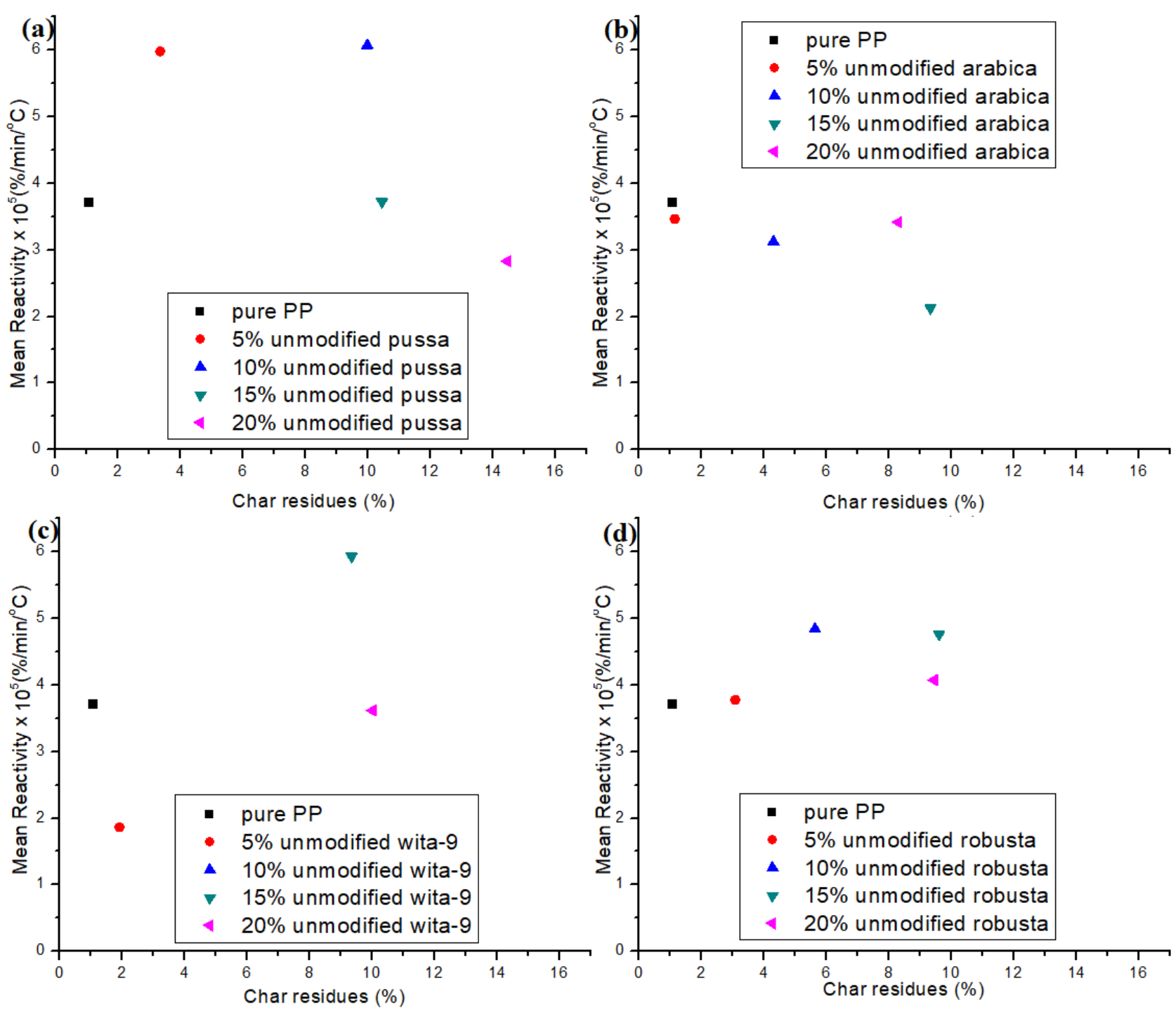

Fig. 5: Mean reactivity vs char residues for unmodified bio-char reinforced PP a) Pussa rice b) Arabica coffee c) Wita-9 rice d) Robusta coffee 

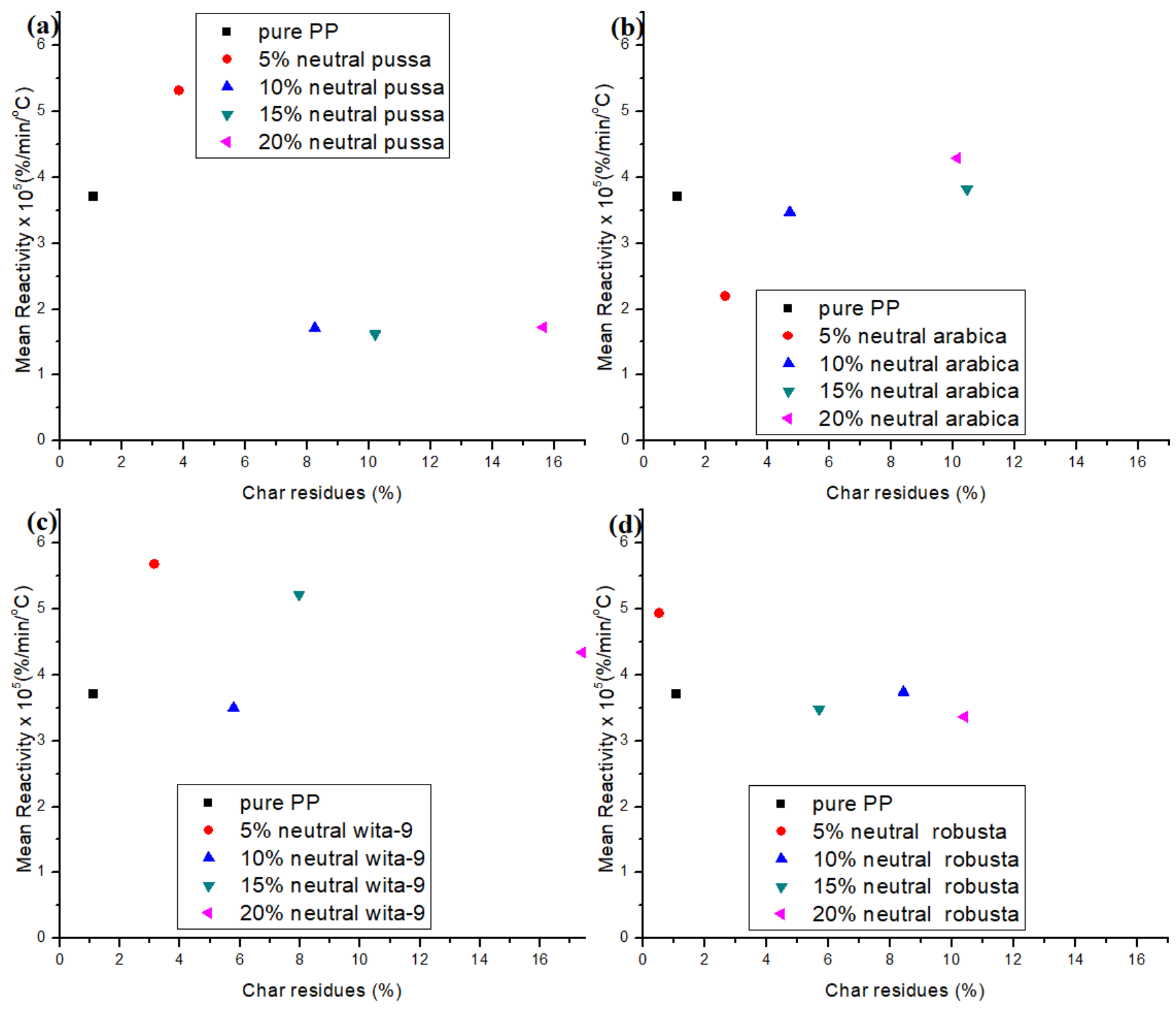

Fig. 6: Mean reactivity vs char residues for neutral bio-char reinforced PP a) Pussa rice b) Arabica coffee c) Wita-9 rice d) Robusta coffee

\subsection{Reactivity}

Reactivity analysis of the developed fiber-reinforced PP samples was obtained by the Ghetti method [48]. The results for the obtained mean reactivities at maximum weight loss are shown in Figures 5-7. The highest mean reactivity attained was $6.1 \times 10^{-5} \% /$ minute $/{ }^{\circ} \mathrm{C}$ obtained when $10 \%$ unmodified Pussa rice husks bio-char was used to reinforce PP (see Figure 5a). For coffee husks, the highest mean reactivity attained was $5.0 \times 10^{-5}$ $\% /$ minute $/{ }^{\circ} \mathrm{C}$ obtained when $5 \%$ neutral Robusta coffee husks bio-char was used to reinforce PP (see Figure 6d). A clear trend is hard to note but, increase in filler loading leads to a reduction in mean reactivities for fiber-reinforced PP loaded with modified and unmodified Arabica coffee, neutral and modified Robusta coffee material as well as modified Pussa rice bio-char material.

The reductions in mean reactivities with increasing filler loadings are attributable to the fact that inclusion filler material reduces the amount of meltable matrix in the fiber-reinforced PP [2]. Another reason for this reduction could be high char conversion time which provides multiple insulative layers in the fiber-reinforced PP [49]. 

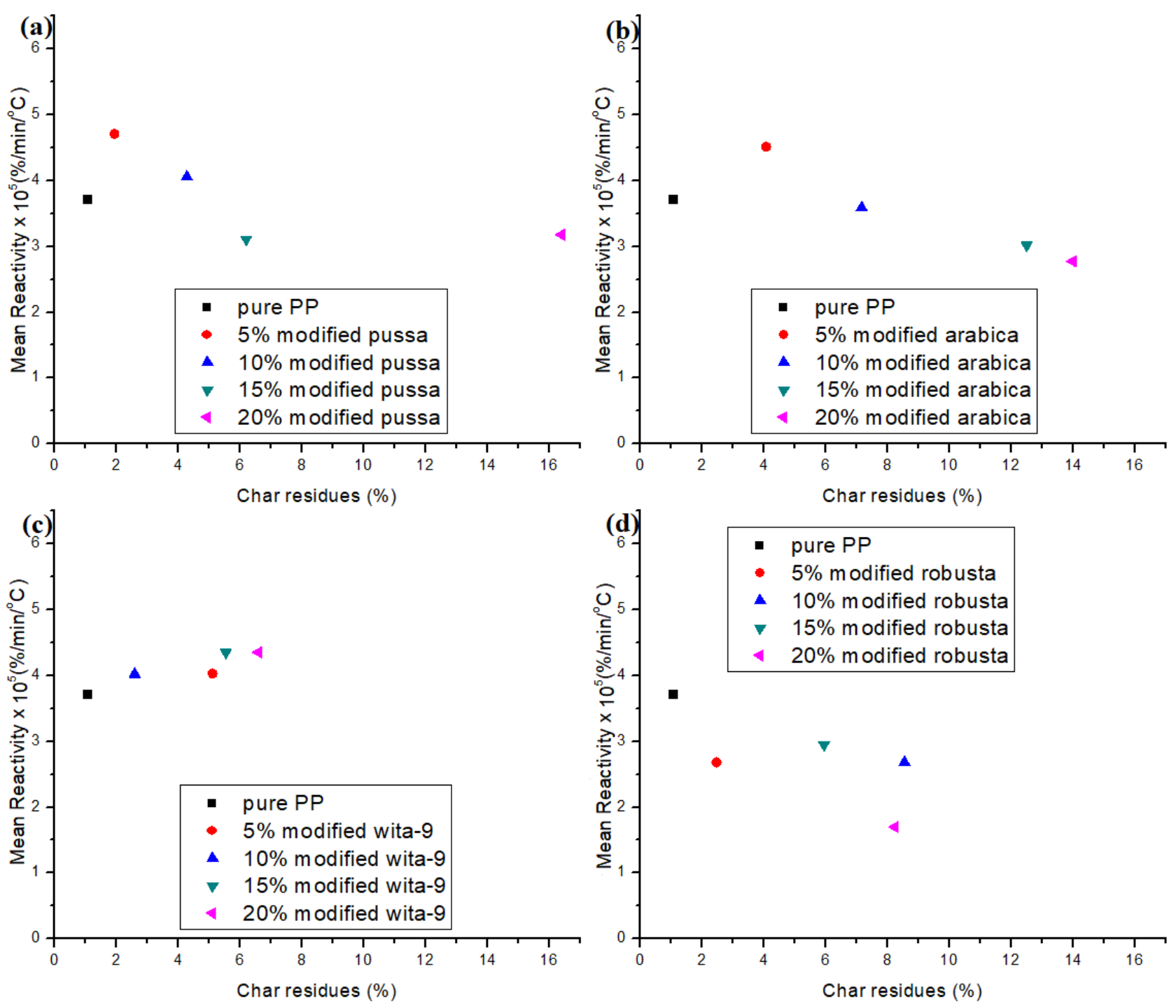

Fig. 7: Mean reactivity vs char residues for modified bio-char reinforced PP a) Pussa rice b) Arabica coffee c) Wita-9 rice d) Robusta coffee

Mean reactivity versus char residues plots gives an understanding of the time at which the peak temperature is reached during combustion of the fiber-reinforced plastics (see Figures 5-8). Basically, it shows the ratio of peak temperature to time at which the peak temperature is reached. Generally, for bio-char reinforced PP, it can be seen that this ratio increases with increasing filler loading. The trend is noticed clearly in unmodified Robusta coffee, neutral Arabica coffee and modified Wita-9 rice husks bio-char reinforced PP. This therefore reflects that higher temperatures are required to reach peak decompositions of the developed plastics. This is because inclusion of rice and coffee husks bio-char filler material reduces the meltable matrix [2].

It should be noted that this ratio has a relationship with the mechanical properties of fiber-reinforced plastics. A higher ratio signifies good mechanical properties (higher tensile strength and Young's modulus as well as lower elongations at break) because fiber in the fiber-reinforced plastic takes longer to generate volatiles, resulting in porosity [50]. Additionally, pre-treatment has been noted to increase decomposition temperatures (and therefore ratio of the mean reactivity to char residues) of fiber material because the treatment removes 
natural and artificial impurities which renders fibers more hydrophobic and thus increases adhesion properties with the polymer matrix, which enhance mechanical properties [16].

Another explanation the ratio could bring about is that of activation energy. This is the energy required to start a combustion reaction. This follows that a higher ratio is synonymous with higher activation energy and therefore low reaction index with oxygen/air [51]. This is so because in conditions where the reaction with oxygen/air is low, the peak temperature reached during combustion of fiber-reinforced plastics is always at maximum. Inclusion of bio-char filler material therefore leads to an increasing ratio and therefore higher activation energy is required to onset degradation of the fiber-reinforced plastic. It is such plastics that are desired in applications that require high flame retardancy properties.

Figure 8 shows the ratio of mean reactivity to char residues on a filler loading aspect. In Figure 8a, it is seen that the ratios are low as shown by the dense appearance of data points on the left hand side of the figure, compared to the ratios in Figure 8d. It is obvious that increase in filler loading causes an increasing trend in the ratio of mean reactivity to char residues. This increasing ratio is observed by the right-hand shift of points as filler loading increases. This follows that as filler loading increases, the fiber-reinforced plastic increasingly reaches higher peak temperatures in a given thermal decomposition time and therefore this signifies improving thermal properties. This is because of increasing char and volatile matter formation levels as mean reactivity increases [52].
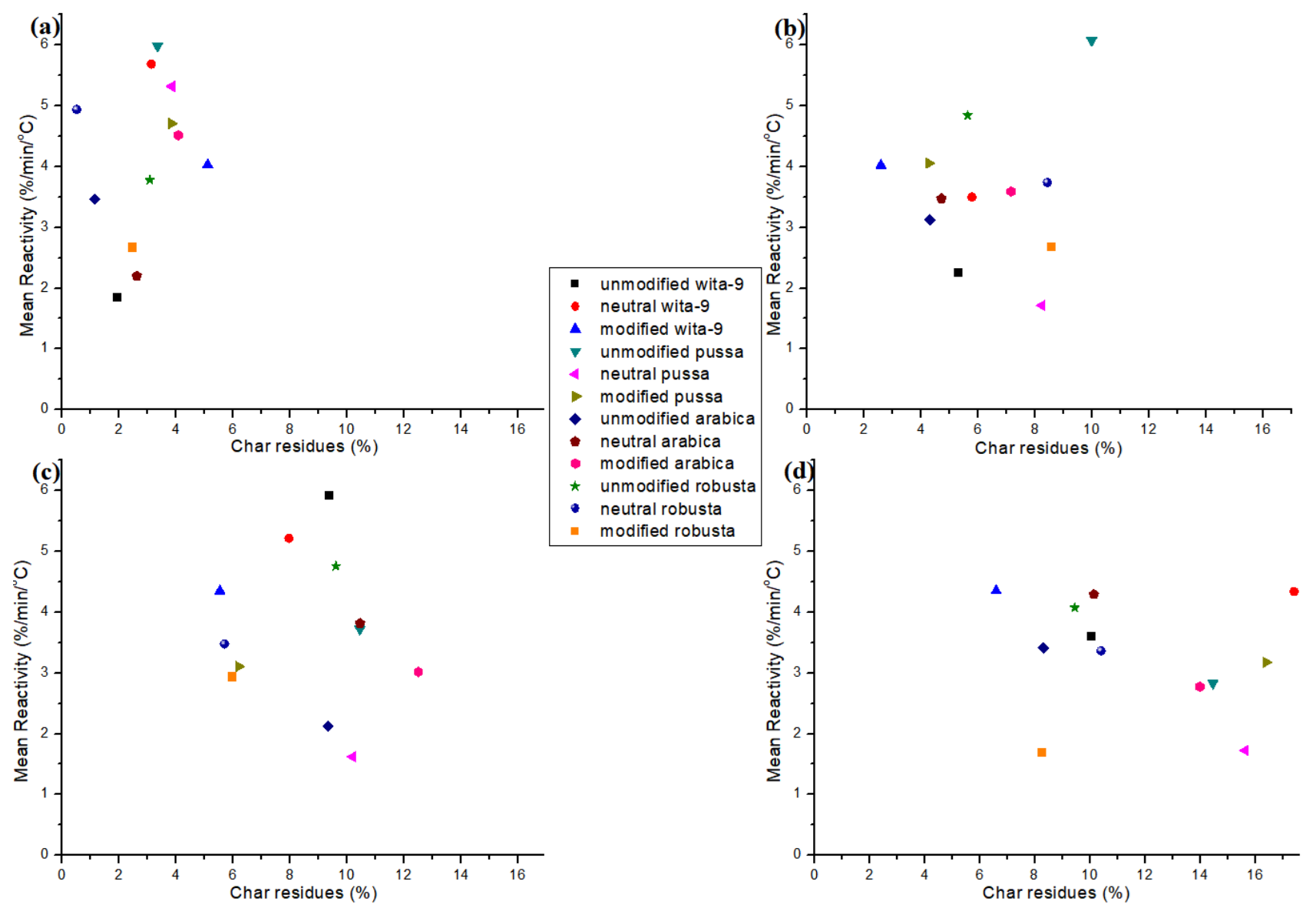

Fig. 8: Mean reactivity vs char residues for developed bio-char reinforced PP with various filler loadings a) $5 \%$ b) $10 \%$ c) $15 \%$ d) $20 \%$ 


\section{CONCLUSIONS}

In this work, melt mixing coupled with compression molding was used to produce fiber-reinforced plastics. With this preparation method, a homogeneous composite material was obtained. Thermogravimetric analysis of fiber-reinforced PP made with bio-chars of Arabica and Robusta coffee husks as well as Pussa and Wita-9 rice husks was carried. Thermogravimetry was carried out on an Eltra Thermostep thermogravimetric analyzer under nitrogen atmosphere at a heating rate of $20^{\circ} \mathrm{C} / \mathrm{min}$. It was found that rate of weight loss for pure PP was faster than those of fiber-reinforced PP. Consequently, char residues obtained after combustion were found to be high in the latter. From DTG, the maximum rate of decomposition was found to be much lower for fiberreinforced PP compared to that of pure PP. Peak temperatures generally increased with increase in filler loading. Mean reactivities ranged between $1.6 \times 10^{-5} \% /$ minute $/{ }^{\circ} \mathrm{C}-6.1 \times 10^{-5} \% /$ minute $/{ }^{\circ} \mathrm{C}, 1.9 \times 10^{-5}$ $\% /$ minute $/{ }^{\circ} \mathrm{C}-5.9 \times 10^{-5} \% /$ minute $/{ }^{\circ} \mathrm{C}, 2.1 \times 10^{-5} \% /$ minute $/{ }^{\circ} \mathrm{C}-4.5 \times 10^{-5} \% /$ minute $/{ }^{\circ} \mathrm{C}, 1.7 \times 10^{-5} \% /$ minute $/{ }^{\circ} \mathrm{C}$ $4.9 \times 10^{-5} \% /$ minute $/{ }^{\circ} \mathrm{C}$ for Pussa rice, Wita-9 rice, Arabica coffee and Robusta coffee respectively. Increase in filler content in the fiber-reinforced PP led to an increase in the ratio of peak temperature to time taken to reach the peak temperature, signalling improving mechanical and thermal properties. The alkali pre-treatment process caused the fibers to swell and it removed the artificial and natural impurities from the fiber surface. In short, due to the improvement in thermal stability with the inclusion of bio-chars in PP, application in Electrical appliances is highly recommended.

\section{ACKNOWLEDGMENT}

The authors would like to acknowledge the Volkswagen Foundation that provided support towards this work under grant number 96655 .

\section{REFERENCES}

[1] H.G. Premalal, H. Ismail, A. Baharin, Comparison of the mechanical properties of rice husk powder filled polypropylene composites with talc filled polypropylene composites, Polymer Testing 21(7) (2002) 833-839.

[2] V.A. Yiga, S. Pagel, M. Lubwama, S. Epple, P.W. Olupot, C. Bonten, Development of fiber-reinforced polypropylene with $\mathrm{NaOH}$ pretreated rice and coffee husks as fillers: Mechanical and thermal properties, Journal of Thermoplastic Composite Materials, (2019) 0892705718823255.

[3] R. Jeencham, N. Suppakarn, K. Jarukumjorn, Effect of flame retardants on flame retardant, mechanical and thermal properties of sisal fiber/ pp composites, Compos Part B Eng. 56 (2007) 249-253.

[4] H.S. Yang, H.J. Kim, H.J. Park, B.J. Lee, T.S. Hwang, Effect of compatibilizing agents on rice-husk flour reinforced polypropylene composites, Composite Structures 77(1) (2007) 45-55.

[5] M. Lubwama, V.A. Yiga, Characteristics of briquettes developed from rice and coffee husks for domestic cooking applications in Uganda, Renewable energy 118 (2018) 43-55.

[6] M.Y. Tan, N. Kuan, H. Tien, M.C. Lee, Characterization of Alkaline Treatment and Fiber Content on the Physical, Thermal, and Mechanical Properties of Ground Coffee Waste/Oxobiodegradable HDPE Biocomposites, International Journal of Polymer Science (2017) 1-12.

[7] K.C. Reis, L. Pereira, I.C.N.A. Melo, J.M. Marconcini, P.F. Trugilho, G.H.D. Tonoli, Particles of coffee wastes as reinforcement in polyhydroxybutyrate (PHB) based composites, Materials Research 18(3) (2015) 546-552.

[8] R.S. Chen, S. Ahmad, S. Gan, Rice husk bio-filler reinforced polymer blends of recycled HDPE/PET: Three-dimensional stability under water immersion and mechanical performance, Polymer Composites 39(8) (2018) 2695-2704.

[9] N.D. Yaacab, H. Ismail, S.S. Ting, Potential use of paddy straw as filler in poly lactic acid/paddy straw powder biocomposite: Thermal and thermal properties, Procedia Chemistry 19 (2016) 757-762.

[10] R.S. Chen, M.N. Salleh, M.H. Ab Ghani, S. Ahmad, S. Gan, Biocomposites based on rice husk flour and recycled polymer blend: Effects of interfacial modification and high fibre loading, BioResources 10(4) (2015) 6872-6885.

[11] C.U. Atuanya, S.A. Olaitan, C.C. Akagu, O.D. Onukwuli, M.C. Menkiti, Effect of rice husk filler on mechanical properties of polyethylene matrix composite, International Journal of Current Research and Review 5(15) (2013) 111-118.

[12] S.L. Fávaro, M.S. Lopes, A.G.V. de Carvalho Neto, R.R. de Santana, E. Radovanovic, Chemical, morphological, and mechanical analysis of rice husk/post-consumer polyethylene composites, Composites Part A: Applied Science and Manufacturing 41(1) (2010) 154-160. 
[13] A.A. Yussuf, I. Massoumi, A. Hassan, Comparison of polylactic acid/kenaf and polylactic acid/rise husk composites: the influence of the natural fibers on the mechanical, thermal and biodegradability properties, Journal of Polymers and the Environment 18(3) (2010) 422-429.

[14] S.M.L. Rosa, E.F. Santos, C.A. Ferreira, S.M.B. Nachtigall, Studies on the properties of rice-husk-filled-PP composites: effect of maleated PP, Materials Research 12(3) (2009) 333-338.

[15] H. Li, M.J. La Guardia, H. Liu, R.C. Hale, T.M. Mainor, E. Harvey, ... P.A. Peng, Brominated and organophosphate flame retardants along a sediment transect encompassing the Guiyu, China e-waste recycling zone, Science of The Total Environment 646 (2019) 58-67.

[16] T.P. Molaba, S. Chapple, M.J. John, Flame retardant treated flax fibre reinforced phenolic composites: Ageing and thermal characteristics, Fire and Materials 42(1) (2018) 50-58.

[17] M.V. Prabhakar, T. Rajasekaran, Machinability and flammability properties of sisal fiber reinforced polymer composites, IOP Conf Series. Materials science and Engineering. 402 (2018).

[18] H. Tang, X.B. Zhou, X.L. Liu, Effect of magnesium hydroxide on the flame retardant properties of unsaturated polyester resin, Procedia Engineering 52 (2013) 336-341.

[19] S. Hazer, M. Coban, A. Aytac, Effects of ammonium polyphosphate and triphenyl phosphate on the flame retardancy, thermal, and mechanical properties of glass fiber-reinforced PLA/PC composites, Fire and Materials 43(3) (2019) 277-282.

[20] J. Lazko, N. Landercy, F. Laoutid, L. Dangreau, M.H. Huguet, O. Talon, Flame retardant treatments of insulating agro-materials from flax short fibres, Polymer degradation and stability 98(5) (2013) 1043-1051.

[21] R. Rangaprasad, K. Rangan, Y.B. Vasudeo, Halogenated and non-halogenated flame retardant additives in polypropylene (PP) homopolymer for battery applications, Polymers and Polymer Composites 10(1) (2002) 33-36.

[22] N.U. Loredo, J.S. Bermejo, Enhanced flame retardancy of flax bio-composites for the construction market, Journal of Facade Design and Engineering 4(1-2) (2016) 67-76.

[23] O. Das, A.K. Sarmah, D.A. Bhattacharyya, A novel approach in organic waste utilization through biochar addition in wood/polypropylene composites, Waste management 38 (2018) 132-140.

[24] Q. Zhang, W. Yi, Z. Li, L. Wang, H. Cai, Mechanical properties of rice husk biochar reinforced high density polyethylene composites, Polymers 10(3) (2018) 286 1-10.

[25] N. Orang, H.O.N.G.H.I. Tran, Effect of feedstock moisture content on biomass boiler operation, Tappi J. 14 (2015) $629-637$.

[26] J. Werther, M. Saenger, E.U. Hartge, T. Ogada, Z. Siagi, Combustion of agricultural residues, Progress in energy and combustion science 26(1) (2000) 1-27.

[27] F. Wang, S. Zhou, M. Yang, Z. Chen, S. Ran, Thermo-mechanical performance of polylactide composites reinforced with alkali-treated bamboo fibers, Polymers 10(4) (2018) 401.

[28] L. Shumao, R. Jie, Y. Hua, Y. Tao, Y. Weizhong, Influence of ammonium polyphosphate on the flame retardancy and mechanical properties of ramie fiber-reinforced poly (lactic acid) biocomposites, Polymer International 59(2) (2010) 242-248.

[29] S. Chapple, R. Anandjiwala, Flammability of natural fiber-reinforced composites and strategies for fire retardancy: a review, Journal of Thermoplastic Composite Materials 23(6) (2010) 871-893.

[30] O. Das, A.K. Sarmah, D. Bhattacharyya, Biocomposites from waste derived biochars: mechanical, thermal, chemical, and morphological properties, Waste management 49 (2016) 560-570.

[31] Y. Nouar, S. Nekkaa, M. Fernández-García, D. López, The thermal and thermomechanical behaviors of Spartium junceum flour reinforced polypropylene composites: effects of treatment and flour content, Composite Interfaces 25(12) (2018) 1067-1089.

[32] B. Souza, A. Moreira, A. Teixeira, TG-FTIR coupling to monitor the pyrolysis products from agricultural residues, Journal of thermal analysis and calorimetry 97(2) (2009) 637-642.

[33] N. Sgriccia, M.C. Hawley, Thermal, morphological, and electrical characterization of microwave processed natural fiber composites, Composites Science and Technology 67(9) (2007) 1986-1991.

[34] A.N. Frone, C.A. Nicolae, R.A. Gabor, D.M. Panaitescu, Thermal properties of water-resistant starch-polyvinyl alcohol films modified with cellulose nanofibers, Polymer degradation and stability 121 (2015) 385-397.

[35] N. Saba, A. Safwan, M.L. Sanyang, F. Mohammad, M. Pervaiz, M. Jawaid, ... M. Sain, Thermal and dynamic mechanical properties of cellulose nanofibers reinforced epoxy composites, International journal of biological macromolecules 102 (2017) 822-828.

[36] X. Chen, Y. Ma, Y. Cheng, A. Zhang, W. Liu, Enhanced mechanical and flame-resistant properties of polypropylene nanocomposites with reduced graphene oxide-functionalized ammonium polyphosphate and pentaerythritol, Journal of Applied Polymer Science, (2019) 48036.

[37] M.R. Rahman, S. Hamdan, E. Jayamani, A. Kakar, M.K.B. Bakri, F.A.B.M. Yusof, Tert-butyl catechol/alkaline-treated kenaf/jute polyethylene hybrid composites: impact on physico-mechanical, thermal and morphological properties, Polymer Bulletin 76(2) (2019) 763-784.

[38] H. Haykıri-Açma, Combustion characteristics of different biomass materials, Energy Conversion and Management 44(1) (2003) 155-162.

[39] J. Lin, Z. Yang, X. Hu, G. Hong, S. Zhang, W. Song, The effect of alkali treatment on properties of dopamine modification of bamboo fiber/polylactic acid composites, Polymers 10(4) (2018) 403 1-12. 
[40] D. Kada, A. Koubaa, G. Tabak, S. Migneault, B. Garnier, A. Boudenne, Tensile properties, thermal conductivity, and thermal stability of short carbon fiber reinforced polypropylene composites, Polymer Composites 39(2) (2018) 664-670.

[41] Q. Zhao, B. Zhang, H. Quan, R.C. Yam, R.K. Yuen, R.K. Li, Flame retardancy of rice husk-filled high-density polyethylene ecocomposites, Composites Science and technology 69(15-16) (2009) 2675-2681.

[42] N. Feng, X. Wang, D. Wu, Surface modification of recycled carbon fiber and its reinforcement effect on nylon 6 composites: Mechanical properties, morphology and crystallization behaviors, Current Applied Physics 13(9) (2013) 2038-2050.

[43] M. Jacob, J. Jose, S. Jose, K.T. Varughese, S. Thomas, Viscoelastic and thermal properties of woven-sisal-fabric-reinforced natural-rubber biocomposites, Journal of applied polymer science 117(1) (2010) 614-621.

[44] M.M. Kabir, H. Wang, K.T. Lau, F. Cardona, T. Aravinthan, Mechanical properties of chemically-treated hemp fibre reinforced sandwich composites, Composites Part B: Engineering 43(2) (2012) 159-169.

[45] F. Zhu, Composition, structure, physicochemical properties, and modifications of cassava starch, Carbohydrate Polymers 122 (2015) 456-480.

[46] V.A. Yiga, M. Lubwama, P.W. Olupot, Effect of Alkaline Surface Modification and Carbonization on Biochemical Properties of Rice and Coffee Husks for Use in Briquettes and Fiber-Reinforced Plastics. Journal of Natural Fibers, (2019). https://doi.org/10.1080/15440478.2019.1642824.

[47] A.R. Zimmerman, B. Gao, M.Y. Ahn, Positive and negative carbon mineralization priming effects among a variety of biocharamended soils, Soil Biology and Biochemistry 43(6) (2011) 1169-1179.

[48] P. Ghetti, L. Ricca, L. Angelini, Thermal analysis of biomass and corresponding pyrolysis products, Fuel 75(5) (1996) $565-573$.

[49] S. Munir, S.S. Daood, W. Nimmo, A.M. Cunliffe, B.M. Gibbs, Thermal analysis and devolatilization kinetics of cotton stalk, sugar cane bagasse and shea meal under nitrogen and air atmospheres, Bioresource Technology 100(3) (2009) 1413-1418.

[50] M.V.F. Ferreira, A.C.C. Neves, C.G. de Oliveira, F.P.D. Lopes, F.M. Margem, C.M.F. Vieira, S.N. Monteiro. Thermogravimetric characterization of polyester matrix composites reinforced with eucalyptus fibers, Journal of Materials Research and Technology, 6(4) (2017) 396-400.

[51] N.T. Farrokh, H. Suopajärvi, P. Sulasalmi, T. Fabritius. A thermogravimetric analysis of lignin char combustion, Energy Procedia, 158 (2019) 1241-1248.

[52] H. Wu, X. Li, J.I. Hayashi, T. Chiba, C.Z. Li. Effects of volatile-char interactions on the reactivity of chars from NaCl-loaded Loy Yang brown coal, Fuel, 84(10) (2005) 1221-1228.

[53] V.A. Yiga, M. Lubwama, P.W. Olupot. Thermogravimetric analysis of compression molded rice and coffee husks bio-char reinforced polypropylene, Mendeley Data, (2019) http://dx.doi.org/10.17632/7427nrrbk6.1. 